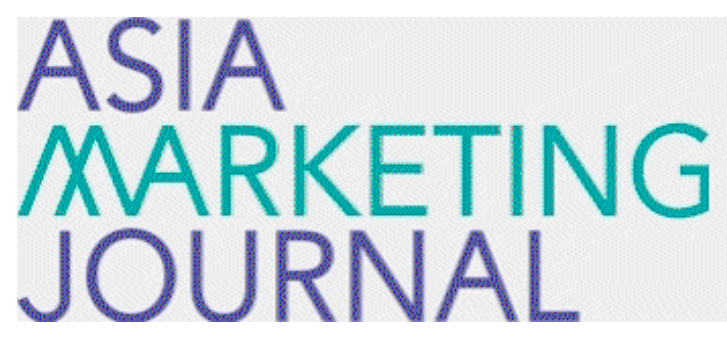

ASIA MARKETING JOURNAL

Volume 18 | Issue 3

Article 4

$10-31-2016$

\title{
Modeling the Relationship between Expected Gain and Expected Value
}

Eugene J. S. Won

Follow this and additional works at: https://amj.kma.re.kr/journal

Part of the Marketing Commons

\section{Recommended Citation}

Won, Eugene J. S. (2016) "Modeling the Relationship between Expected Gain and Expected Value," Asia Marketing Journal: Vol. 18 : Iss. 3 , Article 4.

Available at: https://doi.org/10.15830/amj.2016.18.3.47

This Article is brought to you for free and open access by Asia Marketing Journal. It has been accepted for inclusion in Asia Marketing Journal by an authorized editor of Asia Marketing Journal. 


\title{
Modeling the Relationship between Expected Gain and Expected Value
}

\author{
Eugene J. S. Won*
}

\begin{abstract}
Rational choice theory holds that the alternative with largest expected utility in the choice set should always be chosen. However, it is often observed that an alternative with the largest expected utility is not always chosen while the choice task itself being avoided. Such a choice phenomenon cannot be explained by the traditional expected utility maximization principle. The current study posits shows that such a phenomenon can be attributed to the gap between the expected perceived gain (or loss) and the expected perceived value. This study mathematically analyses the relationship between the expectation of an alternative's gains or losses over the reference point and its expected value, when the perceived gains or losses follow continuous probability distributions. The proposed expected value $(\mathrm{EV})$ function can explain the effects of loss aversion and uncertainty on the evaluation of an alternative based on the prospect theory value function. The proposed function reveals why the expected gain of an alternative should exceed some positive threshold in order for the alternative to be chosen. The model also explains why none of the two equally or similarly attractive options is chosen when they are presented together, but either of them is chosen when presented alone. The EV function and EG-EV curve can extract and visualize the core tenets of the prospect theory more clearly than the value function itself.
\end{abstract}

Key words: prospect theory, loss aversion, value function, expected gain, expected value

\section{Introduction}

In contrast to the traditional utility function based on the concept of fixed utility, the value function was proposed by Kahneman and Tversky (1979) in their prospect theory. Field and $\mathrm{ex}^{-}$ perimental evidence supports the prospect theory value function whereby choices are best explained by assuming that carriers of value are not final

\footnotetext{
* Associate Professor of Marketing, Department of Business Administration, Dongduk Women's University (eugene1@dongduk.ac.kr)
} 
assets, but gains and losses relative to a certain reference point (Tversky and Kahneman, 1991; Barberis et al., 2001). Prospect theory has been proved to be a psychologically more accurate description of decision making, compared to the expected utility theory (Tversky and Simonson, 1993). This study expands on the prospect theory value function by assuming that gains or losses are hardly perceived as deterministic but mostly perceived as probabilistic in real choice situations. If so, the value of a choice alternative will be perceived as stochastic as well and people will have to utilize some representative index such as the expected value as a decision-making criterion, just like the expected utility maximization rule (von Neumann and Morgerstern, 1944; Arrow 1951). This study theoretical investigates the relationship between the expectation of an alternative's perceived gains or losses and the expectation of its value. This study tries to explicate the functional relationship between expected gain(EG) and expected value(EV) with what is called the EV function and discuss its implications. This study reveals that differentiating between the concepts of EG and EV and analyzing the relationship between them can be very useful in extracting the core implications of prospect theory as to consumer choice, especially for the case of choice between equally or similarity attraction alternatives.

\section{The Relationship between Expected Gain and Expected Value Based on a Piecewise Linear Value Function}

Let $A=\{i, j, \cdots\}$ be the set of finite number of available alternatives, and $\nu_{i}^{A}$ denote the value of alternative $i$, dependent on choice set $\mathrm{A}$. Let's assume the simplest functional form reflecting loss aversion, which is a piecewise linear value function (Tversky and Kahneman, 1991; Tversky and Simonson, 1993; Hardie, Johnson and Fader, 1994).

$$
\begin{aligned}
& \nu_{i}^{A}=\alpha \delta_{i}^{A}, \text { if } \delta_{i}^{A} \geq 0, \text { and } \\
& \nu_{i}^{A}=\beta \delta_{i}^{A}, \text { if } \delta_{i}^{A}<0
\end{aligned}
$$

where $\delta_{i}^{A}$ denotes option is gain (if $\delta_{i}^{A}>0$ ) or loss (if $\delta_{i}^{A}<0$ ) relative to the reference point used for evaluating option $i$ in set A. Parameters $\alpha$ and $\beta$ are the gain and loss parameters re $^{-}$ spectively, and the inequality $0<\alpha<\beta$ (loss aversion) is assumed to always hold.

Let's further assume that $\delta_{i}^{A}$ is a random variable that follows a logistic distribution. The expectation of $\delta_{i}^{A}$, or alternatively the expected $\operatorname{gain}(\mathrm{EG})$ of $\mathrm{i}$ is denoted as $\mathrm{E}\left(\delta_{i}^{A}\right)$ and the standard deviation of $\delta_{i}^{A}$ is denoted as $\sigma_{\delta}$ for notational simplicity. The term, expected gain, will be used for referring to expected loss as well by its being negative. The probability den- 
sity function of $\delta_{i}^{A}, \mathrm{f}\left(\delta_{\mathrm{i}}^{\mathrm{A}}\right)$, can be expressed as follows.

$$
\mathrm{f}\left(\delta_{i}^{A}\right)=\frac{\frac{\pi}{\sqrt{3} \sigma_{\delta}} \exp \left[-\frac{\left(\delta_{i}^{A}-\mathrm{E}\left(\delta_{i}^{A}\right)\right) \pi}{\sqrt{3} \sigma_{\delta}}\right]}{\left\{1+\exp \left[-\frac{\left(\delta_{i}^{A}-\mathrm{E}\left(\delta_{i}^{A}\right)\right) \pi}{\sqrt{3} \sigma_{\delta}}\right]\right\}^{2}}
$$

$\nu_{i}^{A}$ also becomes a random variable. If we let $\mathrm{g}\left(\nu_{i}^{A}\right)$ denote the probability density function of $\nu_{i}^{A}$, the $\mathrm{g}\left(\nu_{i}^{A}\right)$ can be derived from Equation (2).

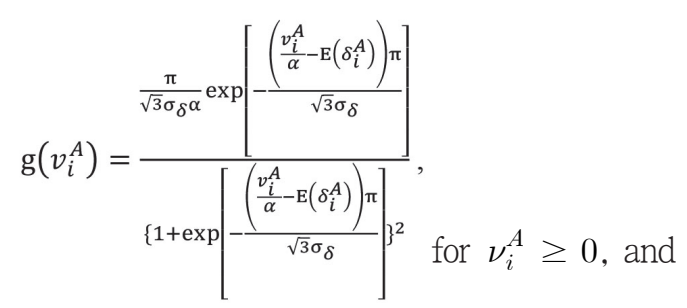

$$
\mathrm{g}\left(v_{i}^{A}\right)=\frac{\frac{\pi}{\sqrt{3} \sigma_{\delta} \beta} \exp \left[-\frac{\left(\frac{v_{i}^{A}}{\beta}-\mathrm{E}\left(\delta_{i}^{A}\right)\right)^{\pi}}{\sqrt{3} \sigma_{\delta}}\right]}{\left\{1+\exp \left[-\frac{\left.\left(\frac{\left.v_{i}^{A}-\mathrm{E}\left(\delta_{i}^{A}\right)\right) \pi}{\sqrt{3} \sigma_{\delta}}\right]\right\}^{2}}{\text { for } \nu_{i}^{A}<0 .}\right.\right.},
$$

If we assume a specific case where $\mathrm{E}\left(\delta_{i}\right)=0$, $\sigma_{\delta}=1, \alpha=1$, and $\beta=2$, the probability density functions for $\delta_{i}^{A}$ and $\nu_{i}^{A}$ will be have such shapes as shown in Figure 1.

Let $\mathrm{E}\left(\nu_{i}^{A}\right)$ denote the expectation of $\nu_{i}^{A}$, which will be alternatively called the expected value $(\mathrm{EV})$ of $\mathrm{i}$. Then $\mathrm{E}\left(\delta_{i}^{A}\right)$ can be calculated as follows.

$$
\begin{gathered}
\mathrm{E}\left(v_{i}^{A}\right)=\int_{-\infty}^{\infty} v_{i}^{A} \cdot \mathrm{g}\left(v_{i}^{A}\right) \mathrm{d} v_{i}^{A} \\
=\int_{-\infty}^{0} v_{i}^{A} \cdot \mathrm{g}\left(v_{i}^{A}\right) \mathrm{d} v_{i}^{A}+\int_{0}^{\infty} v_{i}^{A} \cdot \mathrm{g}\left(v_{i}^{A}\right) \mathrm{d} v_{i}^{A} \\
=\beta \int_{-\infty}^{0} \delta_{i} \frac{\frac{\pi}{\sqrt{3} \sigma_{\delta}} \exp \left[-\frac{\left(\delta_{i}^{A}-\mathrm{E}\left(\delta_{i}^{A}\right)\right) \pi}{\sqrt{3} \sigma_{\delta}}\right]}{\left\{1+\exp \left[-\frac{\left(\delta_{i}^{A}-\mathrm{E}\left(\delta_{i}^{A}\right)\right) \pi}{\sqrt{3} \sigma_{\delta}}\right]\right\}^{2}} \mathrm{~d} \delta_{i}^{A} \\
+\alpha \int_{0}^{\infty} \delta_{i} \frac{\frac{\pi}{\sqrt{3} \sigma_{\delta}} \exp \left[-\frac{\left(\delta_{i}^{A}-\mathrm{E}\left(\delta_{i}^{A}\right)\right) \pi}{\sqrt{3} \sigma_{\delta}}\right]}{\left\{1+\exp \left[-\frac{\left(\delta_{i}^{A}-\mathrm{E}\left(\delta_{i}^{A}\right)\right) \pi}{\sqrt{3} \sigma_{\delta}}\right]\right\}^{2}} \mathrm{~d} \delta_{i}^{A} \\
=\frac{\sqrt{3} \sigma_{\delta} \alpha}{\pi} \ln \left[\frac{1+\exp \left(\frac{\pi \mathrm{E}\left(\delta_{i}^{A}\right)}{\left.\sqrt{3} \sigma_{\delta}\right)}\right.}{\left\{1+\exp \left(-\frac{\pi \mathrm{E}\left(\delta_{i}^{A}\right)}{\sqrt{3} \sigma_{\delta}}\right)\right\}^{k}}\right] \text { (EV function) (4) }
\end{gathered}
$$

〈Figure 1〉 The Probability Density Functions of $\delta_{i}^{A}$ and $\nu_{i}^{A}$ at $\mathrm{E}\left(\delta_{i}\right)=0, \sigma_{\delta}=1, \alpha=1$, and $\beta=2$
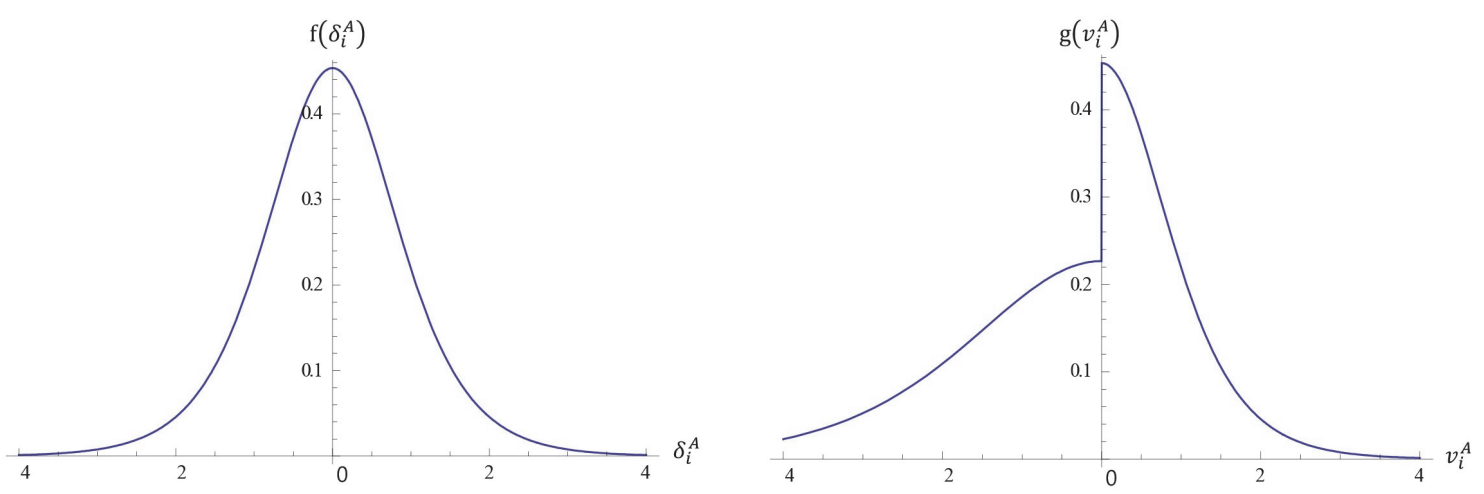
Let the ratio $\frac{\beta}{\alpha}$ be simply denoted as $\mathrm{k}$, whereby the magnitude of $k$ reflects the degree of loss aversion. The other variables assumed to be fixed, $\mathrm{E}\left(\delta_{i}^{A}\right)$ is a monotonic increasing, concave function of $\mathrm{E}\left(\delta_{i}^{A}\right)$. The EG-EV curve in Figure 2 shows the functional relationship between $\mathrm{E}\left(\delta_{i}^{A}\right)$ and $\mathrm{E}\left(\nu_{i}^{A}\right)$ for a specific case where $\alpha=1, \mathrm{k}=2$, and $\sigma_{\delta}=1$. The dotted straight lines in the figure are the asymptote of the curve.

The EG-EV curve crosses the vertical axis below the origin, which means that the EV of an option is negative when the option's EG is zero. People feel like they are losing out when they are provided an option with the same amounts of possible gains and losses, because possible losses loom larger than possible gains. The shape of the curve implies that the EV of an alternative is negative when its EG is positive but smaller than a certain threshold value, i.e., $\mathrm{E}\left(\delta_{i}^{A}\right)<\mathrm{E}\left(\delta_{i}^{A}\right)^{*}$. In order for $\mathrm{E}\left(\nu_{i}^{A}\right)$ to be positive, $\mathrm{E}\left(\delta_{i}^{A}\right)$ should be greater than a certain threshold represented as $\mathrm{E}\left(\delta_{i}^{A}\right)^{*}$ in the figure. An option is perceived as attractive enough to be chosen only when its expected gain is large enough to overcome the people's distaste for possible loss. Calculations based on the EV function show that increased uncertainty about gains or losses $\left(\sigma_{\delta}\right)$ decreases $\mathrm{E}\left(\nu_{i}^{A}\right)$. From Equation (4),

$$
\begin{gathered}
\frac{\partial \mathrm{E}\left(v_{i}^{\mathrm{A}}\right)}{\partial \sigma_{\delta}}=-\frac{\alpha}{\left(1+\exp \left[\frac{\mathrm{E}\left(\delta_{i}^{A}\right) \pi}{\sqrt{3} \sigma_{\delta}}\right)\right) \pi \sigma_{\delta}}\left\{\left[\exp \left(\frac{\mathrm{E}\left(\delta_{i}^{A}\right) \pi}{\sqrt{3} \sigma_{\delta}}\right)+\mathrm{k}\right] \mathrm{E}\left(\delta_{i}^{A}\right) \pi\right. \\
+\sqrt{3} \mathrm{k} \sigma_{\delta}\left[1+\exp \left(\frac{\mathrm{E}\left(\delta_{i}^{A}\right) \pi}{\sqrt{3} \sigma_{\delta}}\right)\right] \ln \left[1+\exp \left(-\frac{\mathrm{E}\left(\delta_{i}^{A}\right) \pi}{\sqrt{3} \sigma_{\delta}}\right)\right] \\
\left.-\sqrt{3} \sigma_{\delta}\left[1+\exp \left(\frac{\mathrm{E}\left(\delta_{i}^{A}\right) \pi}{\sqrt{3} \sigma_{\delta}}\right)\right] \ln \left[1+\exp \left(\frac{\mathrm{E}\left(\delta_{i}^{A}\right) \pi}{\sqrt{3} \sigma_{\delta}}\right)\right]\right\}<0
\end{gathered}
$$

〈Figure 2〉 The EG-EV Curve under the Assumption of a Piecewise Linear Value Function

$$
\left(\sigma_{\delta}=1, \alpha=1, k=2\right)
$$

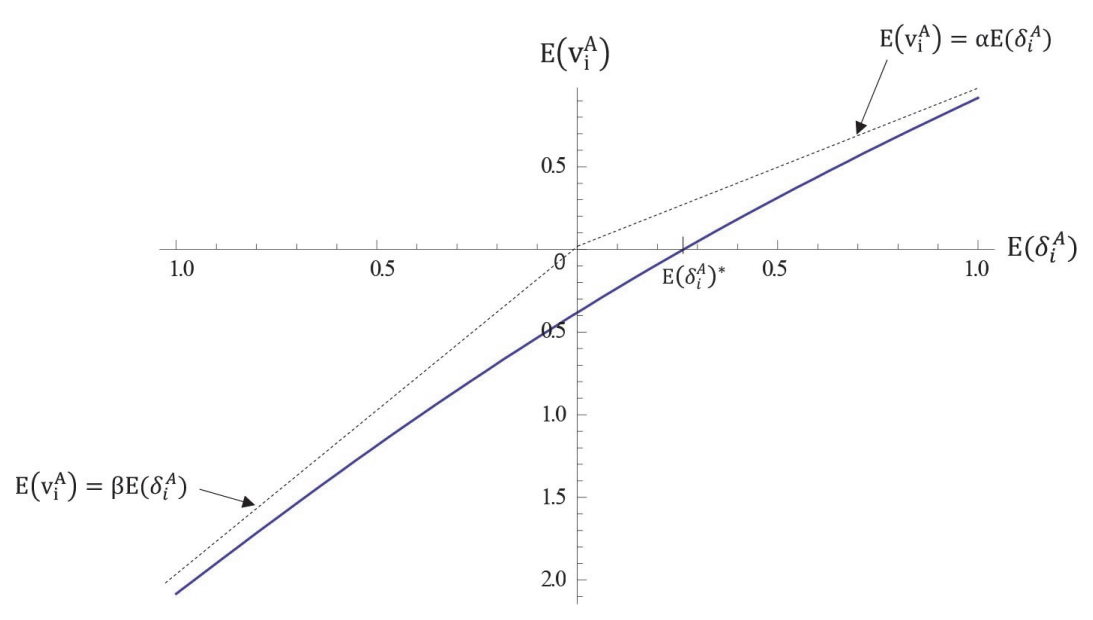


Mathematica Software is used for the calculations throughout the article. Figure 3 shows that reduced uncertainty increases the attractiveness of the option with a constant expected gain. Such a phenomenon is illustrated by an example proposed by Samuelson (1963). Samuelson once offered a colleague the following bet: flip a coin, heads you win $\$ 200$ and tails you lose $\$ 100$. Samuelson reports that his colleague turned this bet down but said that he would be happy to take 100 such bets. He then proved that this pair of choices is irrational, because someone should not be willing to play a bet many times if he is not willing to play it just once. Based on the model proposed in this study, what the aggregation or the repetitions of the same bet does is not to change the expected gain of the bet but to decrease the uncertainty and thus increase the value of the bet.

The EG-EV curve and Samuelson's example are closely related to various choice behaviors including what is called the myopic loss aversion (Benartzi and Thaler 1995; Thaler et al. 1997). Myopic loss aversion is a behavioral concept proposed as an explanation for the equity premium puzzle, which is defined as the difference in returns between equities (stocks) and a risk-free asset such as treasury bills (Mehra and Prescott 1985). Having a long-term perspective often eliminates or diminishes high perceived uncertainty arisen from a myopic(short-term) perspective. Thus, an investor who is prepared to wait a long time before evaluating the outcome of the investment as a gain or loss will find the risky asset (stocks) more attractive than another investor (equally loss aversive, but more myopic) who evaluates the outcome soon or frequently (Thaler et al. 1997). Narrow framing, which is what most people do, increases the perceived risk of the option, which in turn makes the decision maker demand higher expected return (equity premium) to compensate for the high

〈Figure 3〉 The EG-EV curve for Different Values of $\sigma_{\delta}(\alpha=1, \mathrm{k}=2)$

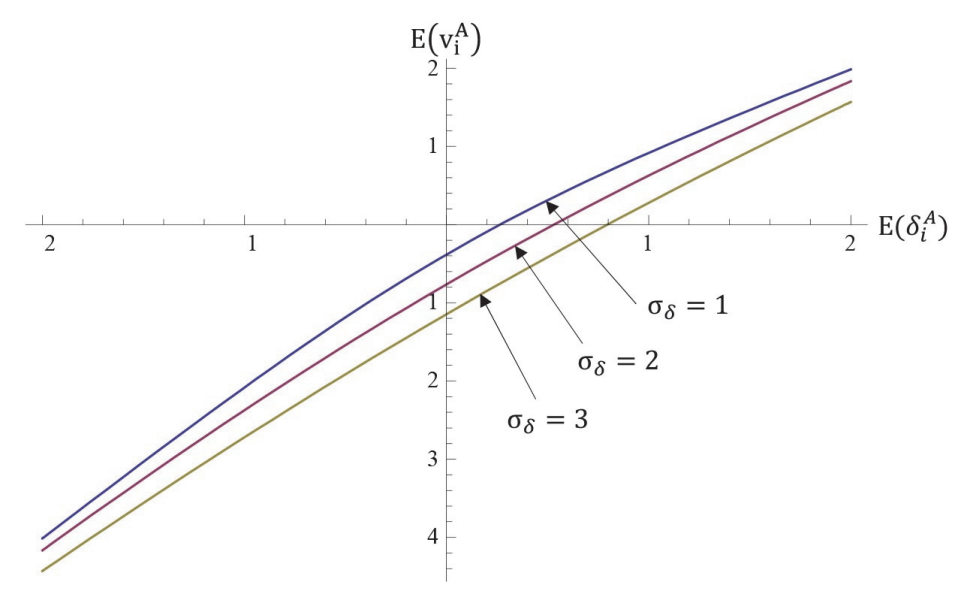

Modeling the Relationship between Expected Gain and Expected Value 51 
risk. As an illustration, Figure 4 shows three different probability distributions of perceived gains generating the same expected value(EV). The figure implies that the expected gain should be correspondingly higher for an alternative with higher uncertainty to provide the same EV. The degree of loss aversion has a direct impact on the EV of an alternative. As the degree of loss aversion gets larger, the EV becomes smaller (Figure 5).

$$
\frac{\partial \mathrm{E}\left(v_{\mathrm{i}}^{\mathrm{A}}\right)}{\partial k}=\frac{-\sqrt{3} \alpha}{\pi} \sigma_{\delta} \ln \left[1+\exp \left(-\frac{\pi \mathrm{E}\left(\delta_{i}^{A}\right)}{\sqrt{3} \sigma_{\delta}}\right)\right]<0
$$

〈Figure 4〉 The Three Distributions of $\delta_{i}^{A}$ Generating the Same Expected Value of Zero $(\alpha=1, k=2)$

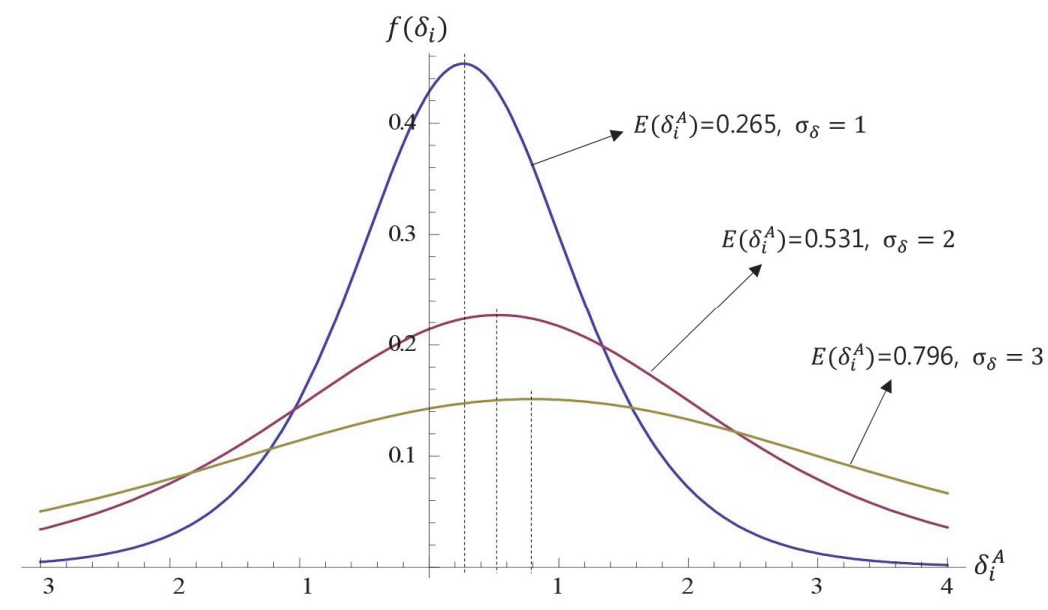

〈Figure 5〉 The EG-EV Curve with Varying Degrees of Loss Aversion $\left(\sigma_{\delta}=1\right)$

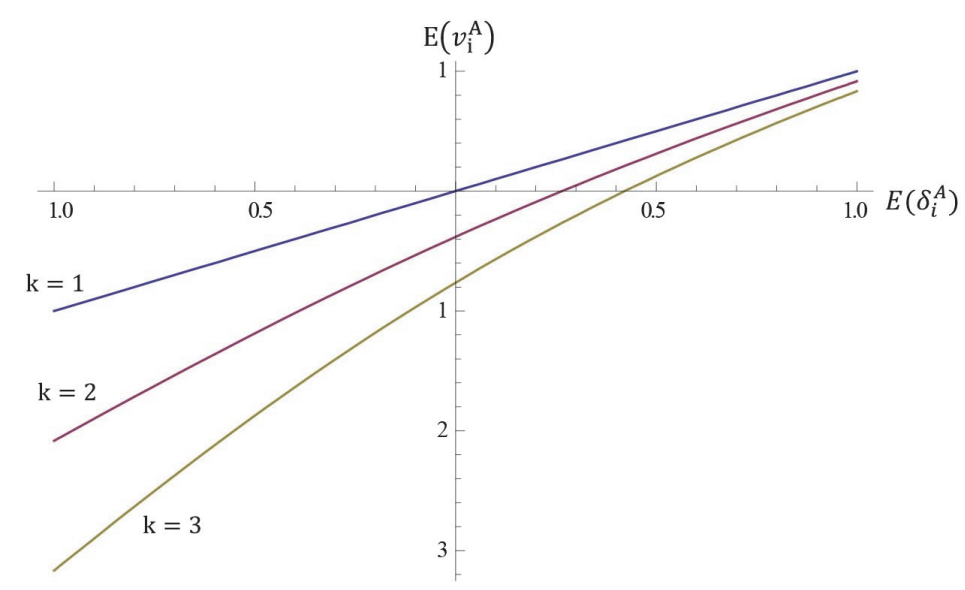

52 ASIA MARKETING JOURNAL Vol. 18 No. 03 October 2016 


\section{The EV Function based on a Value Function Incorporating Decreasing Marginal Sensitivity}

In the previous section a simple piecewiselinear value function is assumed to avoid computational complications in deriving the $\mathrm{EV}$ function. However, the linear approximation of the prospect theory value function is justifiable only when $\delta_{i}^{A}$ is assumed to lie within a relatively narrow range around zero. For more strict theoretical generalization, another important property of the prospect theory value function should be incorporated in the analysis, the decreasing marginal sensitivity. We can adopt a logistic curve to incorporate this property. The original logistic function is slightly modified to incorporate the loss aversion effect as well and the modified version can be distinguishably called the asymmetric logistic function (Figure 6).

$$
\begin{aligned}
& v_{i}^{A}=\mathrm{M}\left(\frac{1}{1+\exp \left(-\mathrm{r} \delta_{i}^{A}\right)}-0.5\right)=\mathrm{M} \frac{1-\exp \left(-\mathrm{r} \delta_{i}^{A}\right)}{2\left(1+\exp \left(-\mathrm{r} \delta_{i}^{A}\right)\right)}, \\
& \text { if } \delta_{i}^{A} \geq 0, \text { and }
\end{aligned}
$$

$$
\begin{aligned}
& v_{i}^{A}=\operatorname{kM}\left(\frac{1}{1+\exp \left(-\mathrm{r} \delta_{i}^{A}\right)}-0.5\right)=k \mathrm{M} \frac{1-\exp \left(-\mathrm{r} \delta_{i}^{A}\right)}{2\left(1+\exp \left(-\mathrm{r} \delta_{i}^{A}\right)\right)}, \\
& \text { if } \delta_{i}^{A}<0
\end{aligned}
$$

$r$ is a positive coefficient, $M$ is a constant implying the upper limit of the value, and $\mathrm{k}$ the degree of loss aversion $(r>0, M>0, k>$ 1). Values of $r$ and $M$ do not affect the theoretical implication of the analysis. As a numerical example, we will simply assume that $\mathrm{k}=2$, $\mathrm{M}=1$ and $\mathrm{r}=\frac{\pi}{\sqrt{3}}$.

If we assume that $\delta_{i}^{A}$ follows a logistic probability distribution as in the previous section, the expected value can be similarly calculated

〈Figure 6〉 The Prospect Theory Value Function Represented with an Asymmetric Logistic Function ( $k=2)$

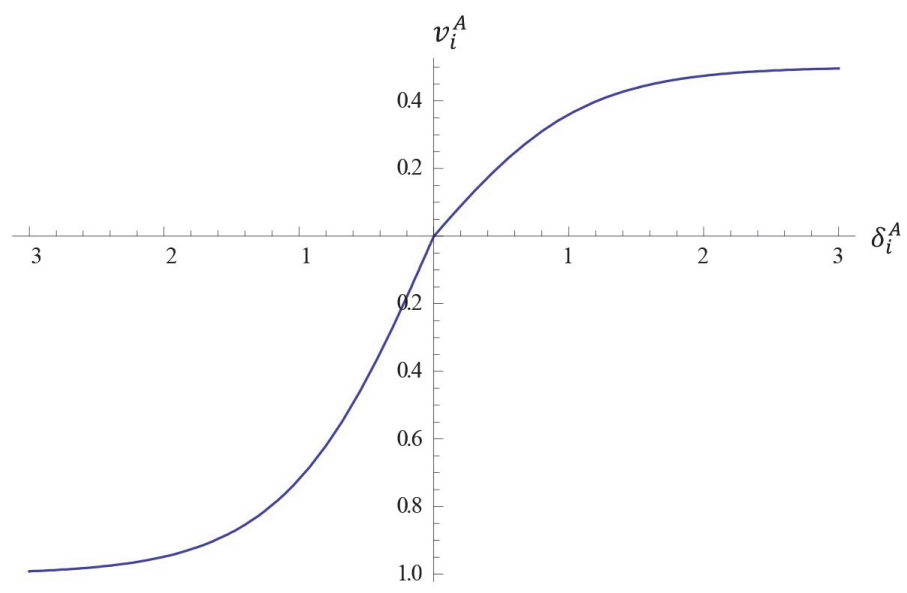


as follows.

$$
\begin{aligned}
& 4 \frac{\mathrm{E}\left(\delta_{i}^{A}\right) \pi}{\sqrt{3}} \exp \left(\frac{\mathrm{E}\left(\delta_{i}^{A}\right) \pi}{\sqrt{3}}\right)+ \\
& \left.2 \exp \left(\frac{\mathrm{E}\left(\delta_{i}^{A}\right) \pi}{\sqrt{3}}\right) \ln \left[1+\exp \left(\frac{\mathrm{E}\left(\delta_{i}^{A}\right) \pi}{\sqrt{3}}\right)\right]\right)
\end{aligned}
$$$$
\mathrm{E}\left(v_{i}^{A}\right)=\int_{-\infty}^{\infty} v_{i}^{A} \mathrm{~g}\left(v_{i}^{A}\right) \mathrm{d} v_{i}^{A}
$$$$
=\mathrm{kM} \int_{-\infty}^{0} \frac{1-\exp \left(-\frac{\delta_{i}^{A} \pi}{\sqrt{3}}\right)}{2\left(1+\exp \left(-\frac{\delta_{i}^{A} \pi}{\sqrt{3}}\right)\right)} \cdot \frac{\frac{\pi}{\sqrt{3} \sigma_{\delta}} \exp \left[-\frac{\left(\delta_{i}^{A}-\mathrm{E}\left(\delta_{i}^{A}\right)\right) \pi}{\sqrt{3} \sigma_{\delta}}\right]}{\left\{1+\exp \left[-\frac{\left(\delta_{i}^{A}-\mathrm{E}\left(\delta_{i}^{A}\right)\right) \pi}{\sqrt{3} \sigma_{\delta}}\right]\right\}^{2}} \mathrm{~d} \delta_{i}^{A}
$$

$+\mathrm{M} \int_{0}^{\infty} \frac{1-\exp \left(-\frac{\delta_{i}^{A} \pi}{\sqrt{3}}\right)}{2\left(1+\exp \left(-\frac{\delta_{i}^{A} \pi}{\sqrt{3}}\right)\right)} \cdot \frac{\frac{\pi}{\sqrt{3} \sigma_{\delta}} \exp \left[-\frac{\left(\delta_{i}^{A}-\mathrm{E}\left(\delta_{i}^{A}\right)\right) \pi}{\sqrt{3} \sigma_{\delta}}\right]}{\left\{1+\exp \left[-\frac{\left(\delta_{i}^{A}-\mathrm{E}\left(\delta_{i}^{A}\right)\right) \pi}{\sqrt{3} \sigma_{\delta}}\right]\right\}^{2}} \mathrm{~d} \delta_{i}^{A}$

For $\mathrm{M}=1, \mathrm{k}=2, \sigma_{\delta}=1, \mathrm{E}\left(\nu_{i}^{A}\right)$ can be calculated as follows and the EG-EV curve can be drawn as shown in Figure 7.

$$
\begin{aligned}
& \mathrm{E}\left(v_{i}^{A}\right)=\frac{1}{2\left(-1+\exp \left(\frac{\mathrm{E}\left(\delta_{i}^{A}\right) \pi}{\sqrt{3}}\right)\right)^{2}}\left(-2+\exp \left(\frac{\mathrm{E}\left(\delta_{i}^{A}\right) \pi}{\sqrt{3}}\right)\right. \\
& +\exp \left(\frac{2 \mathrm{E}\left(\delta_{i}^{A}\right) \pi}{\sqrt{3}}\right)-\exp \left(\frac{\mathrm{E}\left(\delta_{i}^{A}\right) \pi}{\sqrt{3}}\right) \ln [4]-
\end{aligned}
$$

The existence of a positive threshold level as $\mathrm{E}\left(\delta_{i}^{A}\right)^{*}$ in Figure 2 is also evident in the case of a logistic value function. The EV curves can be drawn for different values of perceived uncertainty (Figure 8) and for different degrees of loss aversion (Figure 9). Figure 8 shows that, as the prospect theory states, a more uncertain option is avoided in the gain region but is preferred in the loss region. To be more exact, a small negative value of $\mathrm{E}\left(\delta_{i}^{A}\right)$ becomes the fiducial point where the risk attitude is reversed. The reversal of risk attitude around a certain reference point, which is the core tenet of the prospect theory, can be made explicit with the EG-EV curve.

〈Figure 7〉 The EG-EV Curve Based on a Asymmetric Logistic Value Function ( $k=2, \sigma_{\delta}=1$ )

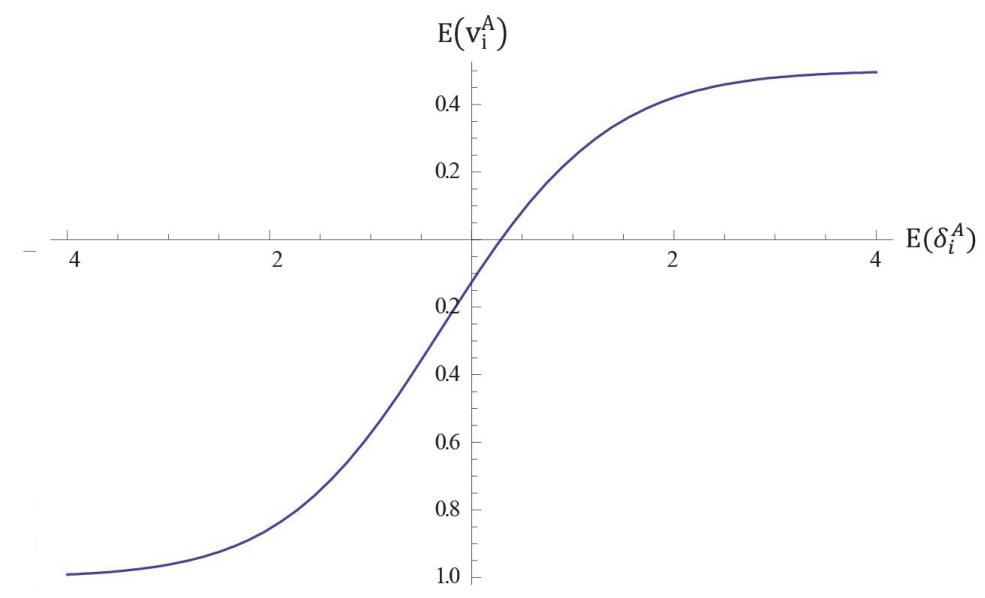

54 ASIA MARKETING JOURNAL Vol. 18 No. 03 October 2016 
〈Figure 8〉 The EG-EV Curve for Different Values of $\sigma_{\delta}$ Based on an Asymmetric Logistic Value Function $(\mathrm{k}=2)$

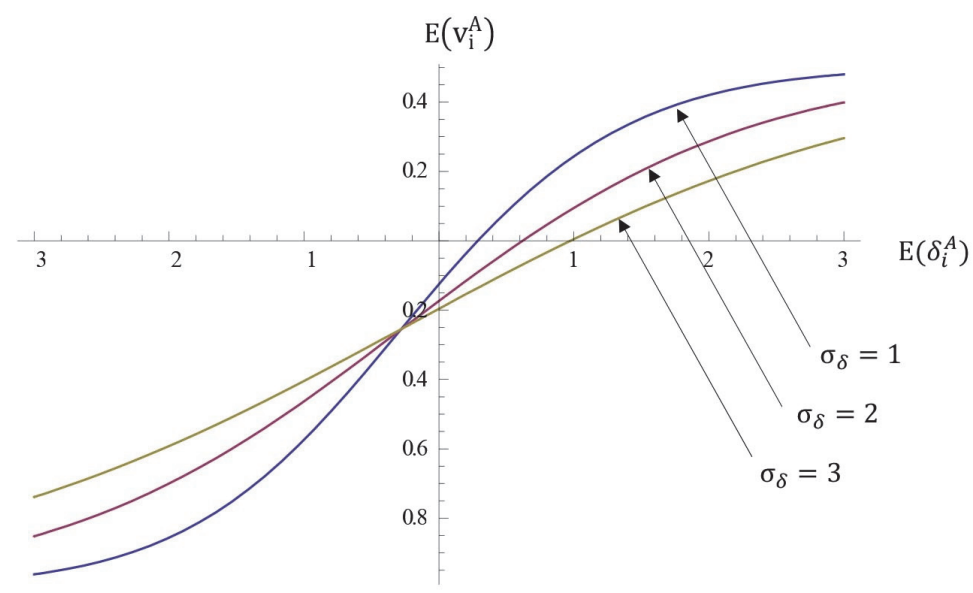

〈Figure 9〉 The EG-EV Curve for Different Values of $\mathrm{k}$ Based on an Asymmetric Logistic Value Function $\left(\sigma_{\delta}=1\right)$

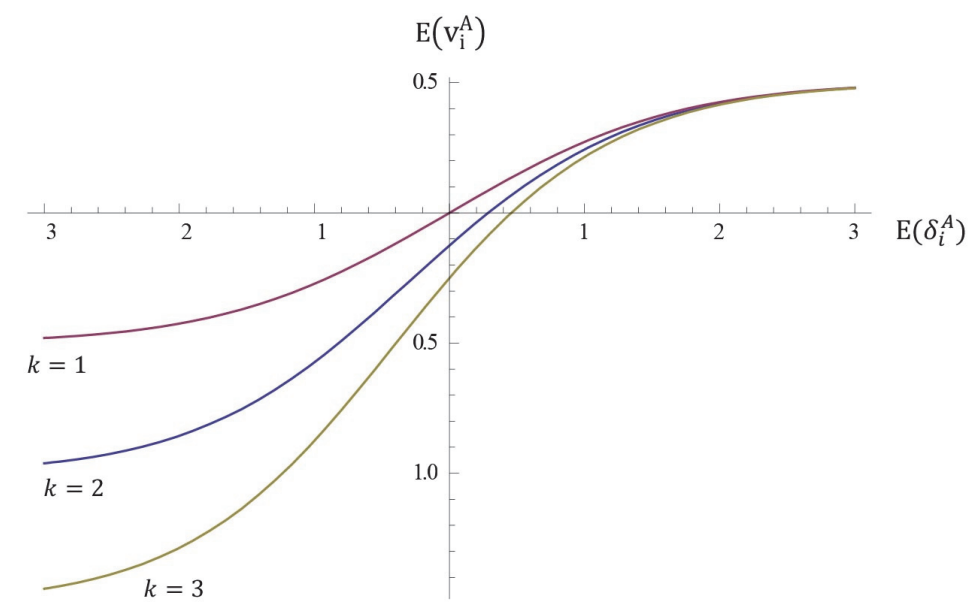

The EG-ERV curve also implies that what has been referred to as "the pioneering advantage' in marketing (Schmalensee 1982; Carpenter and Nakamoto 1989; Kerin et al. 1991; Urban et al. 1986) arises not from the higher expected utility of the pioneer brand but from the higher perceived uncertainty of the later entrants' quality. The perceived uncertainty will decrease dramatically as people's experiences with a new brand accumulate. Thus, a pioneer brand is often preferred to late entrants with similar expected quality but of high uncertainty. Similarly, the sudden explosion of a new product's sales after a certain time interval can be attributed not to the change in expected utility but to the decrease in perceived utility variance (Bass 1969). 
As an additional analysis, another type of value function is considered. In explaining the concept of satisficing heuristic in human decision making, Simon (1955) proposed a discrete value function with the concept of a certain acceptance level and he referred to it as a simple payoff function(p.61, Simon 1955). The payoff is either satisfactory or unsatisfactory. To maintain notational consistency throughout the article, $\delta_{i}^{A}$ will be used to denote the difference between the payoff and the acceptance level. The value of $\delta_{i}^{A}$ being greater or equal to zero refers to the condition where the payoff is satisfactory while $\delta_{i}^{A}$ being negative implies that the payoff is unsatisfactory. The discrete value function is represented by Equation (10) and Figure 10. In Equation (10), Q is some positive constant and $\mathrm{k}$ is degree of loss aversion as in the previous examples $(k>1)$.

$$
\begin{aligned}
& \nu_{i}^{A}=\mathrm{Q}, \quad \text { if } \delta_{i}^{A} \geq 0 \text { and } \\
& \nu_{i}^{A}=-\mathrm{kQ}, \text { if } \delta_{i}^{A}<0 \text { and }
\end{aligned}
$$

The expected value calculated with the assumption of logistically distributed $\delta_{i}^{A}$ is as follows.

$$
\begin{aligned}
\mathrm{E}\left(v_{i}^{A}\right) & =-\mathrm{kQ} \int_{-\infty}^{0} \frac{\frac{\pi}{\sqrt{3} \sigma_{\delta}} \exp \left[-\frac{\left(\delta_{i}^{A}-\mathrm{E}\left(\delta_{i}^{A}\right)\right) \pi}{\sqrt{3} \sigma_{\delta}}\right]}{\left\{1+\exp \left[-\frac{\left(\delta_{i}^{A}-\mathrm{E}\left(\delta_{i}^{A}\right)\right) \pi}{\sqrt{3} \sigma_{\delta}}\right]\right\}^{2}} \mathrm{~d} \delta_{i}^{A} \\
& +\mathrm{Q} \int_{0}^{\infty} \frac{\frac{\pi}{\sqrt{3} \sigma_{\delta}} \exp \left[-\frac{\left(\delta_{i}^{A}-\mathrm{E}\left(\delta_{i}^{A}\right)\right) \pi}{\sqrt{3} \sigma_{\delta}}\right]}{\left\{1+\exp \left[-\frac{\left(\delta_{i}^{A}-\mathrm{E}\left(\delta_{i}^{A}\right)\right) \pi}{\sqrt{3} \sigma_{\delta}}\right]\right\}^{2}} \mathrm{~d} \delta_{i}^{A}
\end{aligned}
$$

If we assume a simple case where $Q=1$ and $\mathrm{k}=2$ and $\sigma_{\delta}=1, \mathrm{E}\left(v_{i}^{A}\right)=\frac{-2+\exp \left[\frac{\left[\delta_{i}^{A} \pi\right.}{\sqrt{3}}\right]}{1+\exp \left[\frac{\delta_{i}^{A} \pi}{\sqrt{3}}\right]}$ and the shape of $\mathrm{E}\left(\nu_{i}^{A}\right)$ can be represented as in Figure 11. Figure 11 implies that the EG-EV func-

〈Figure 10〉 The Discrete Value Function Proposed by Simon (1955) $(k=2, Q=1)$

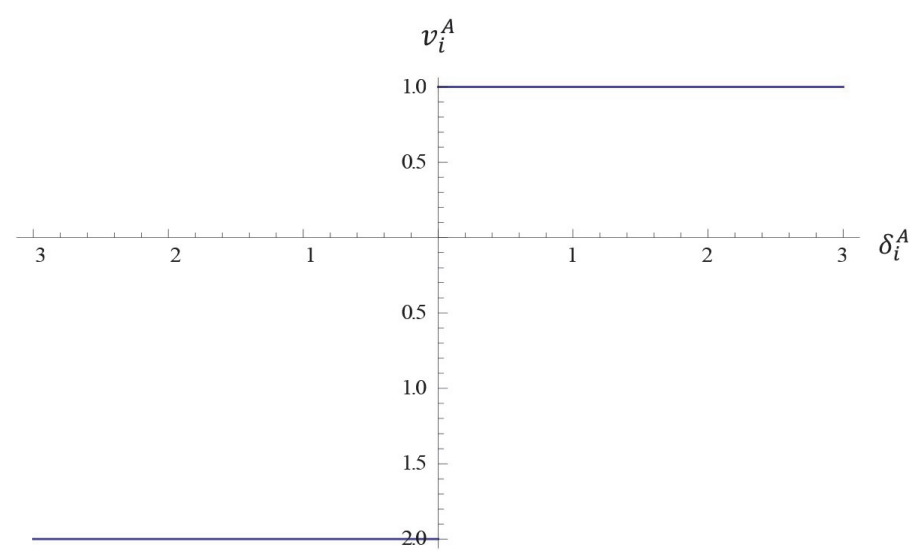


tion based on the discrete value function has a shape similar to the one based on the prospect theory value function. Comparing Figure 7 and Figure 11, we can conclude that Simon's discrete value function and the prospect theory value function have exactly the same implications as to the decision making in the real world where perceived uncertainty is ubiquitous. If people consider an option's payoff falling short of the acceptance level more seriously than its meeting the acceptance level, the expected payoff should be greater than the acceptance level in order for the option to be chose. The combination of the expected value maximization and the type of discrete value function proposed by Simon can also explain the reversal of risk at-

〈Figure 11〉 The EG-EV Curve Based on a Discrete Value Function $(k=2, Q=1)$

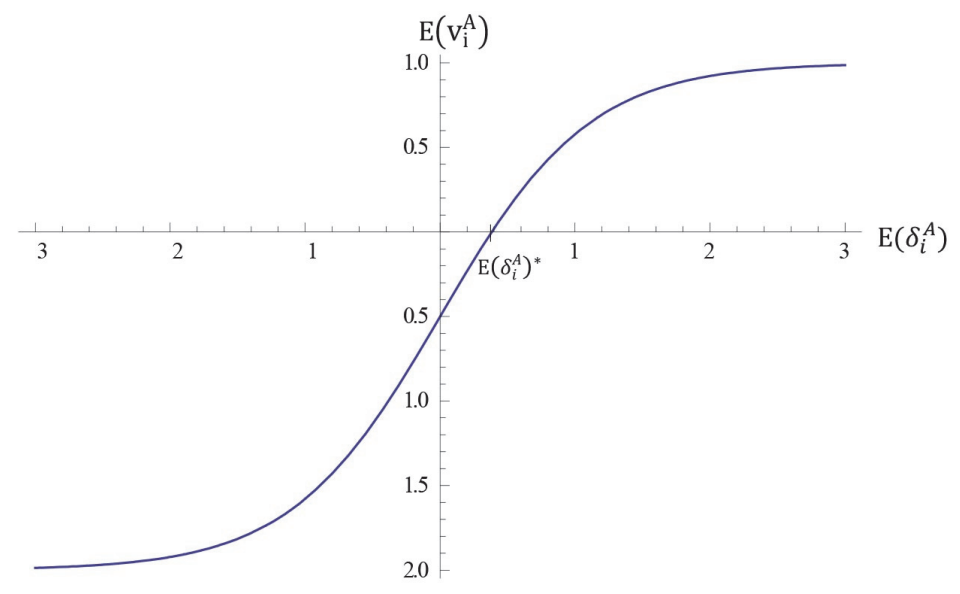

〈Figure 12〉 The EG-EV Curve Based on a Discrete Value Function $(k=2, Q=1)$

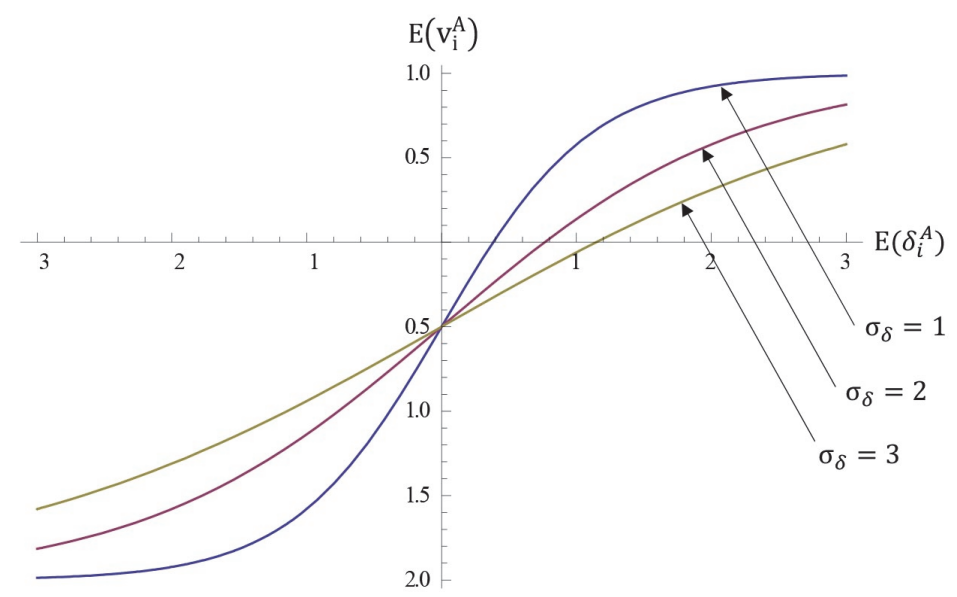

Modeling the Relationship between Expected Gain and Expected Value 57 
titude around a certain reference point. The only difference between the two types of values functions is that in the discrete value function case, risk neutral behavior takes place at $\mathrm{E}\left(\delta_{i}^{A}\right)=0$. The EG-EV curves can function as a part what has been a theoretical missing link between Simon's satisficing theory and the prospect theory.

\section{The EG-EV Curves and Choices from Similarly Attractive Alternatives}

When an alternative is evaluated, the other alternatives in the same choice set are often the most salient and easily available reference points (Tversky and Kahneman, 1991; Hsee and Leclerc, 1998; Anderson and Bower 1973).
If it is assumed that there are only two alternatives, $\mathrm{i}$ and $\mathrm{j}$, in choice set $\mathrm{A}, \delta_{i}^{A}$ becomes option i's gain or loss compared to option $\mathrm{j}$. Likewise, $\delta_{j}^{A}$ becomes that of $\mathrm{j}$ compared to $\mathrm{i}$. Figure 13 shows the EG-EV curves for both options $i$ and $j$ simultaneously, where the value function is assumed as shown in Figure $6(\alpha=1$, $\mathrm{k}=2$, and $\left.\sigma_{\delta}=1\right)$. Note that $\mathrm{E}\left(\delta_{i}^{A}\right)=-\mathrm{E}\left(\delta_{j}^{A}\right)$. When $\mathrm{E}\left(\delta_{i}^{A}\right)$ has a value greater than $\mathrm{E}\left(\delta_{i}^{A}\right)^{*}$, $\mathrm{E}\left(\nu_{i}^{A}\right)$ will be positive. And if $\mathrm{E}\left(\delta_{i}^{A}\right)$ is smaller than $\mathrm{E}\left(\delta_{i}^{A}\right)^{*}, \mathrm{E}\left(\nu_{j}^{A}\right)$ will be positive. If $\left|\mathrm{E}\left(\delta_{i}^{A}\right)\right|$ $\left\langle\mathrm{E}\left(\delta_{i}^{A}\right)^{*}\right.$, both $\mathrm{E}\left(\nu_{i}^{A}\right)$ and $\mathrm{E}\left(\nu_{j}^{A}\right)$ will have negative values, implying that the $\mathrm{EVs}$ of the similarly attractive options can all be negative. The range of $\mathrm{E}\left(\delta_{i}^{A}\right)$ where neither of the given alternatives is deemed sufficiently better than the other to be adopted can be called the zone of choice conflict. Because none of the two similarly attractive alternatives is perceived as

〈Figure 13〉 The EG-EV Curves of both $\mathrm{i}$ and $\mathrm{j}$ and the Zone of Conflict $\left(\beta=1, \alpha=1, \sigma_{\delta}=1\right.$ )

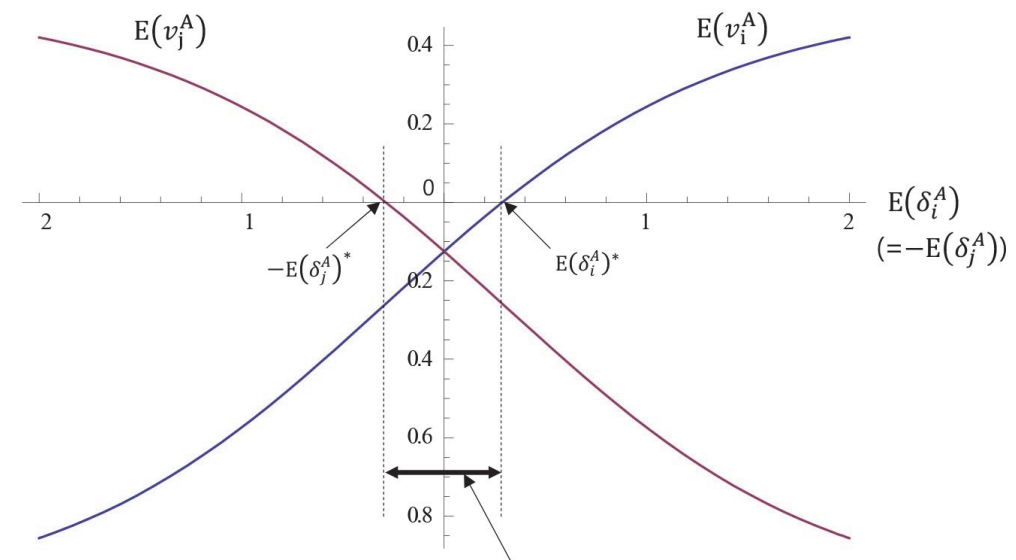

Conflict Zone

58 ASIA MARKETING JOURNAL Vol. 18 №. 03 October 2016 
providing sufficient benefit to be chosen, neither of them is chosen, which is often called the adoption of no choice option(Tversky and Shafir, 1992; Dhar, 1998). The analytical result is consistent with the previous studies supporting the preference construction process that results in small differences in attractiveness among the alternatives increases the preference for and adoption of a no-choice option (Tversky and Shafir, 1992; Dhar, 1998; Dhar and Simonson 2003; Luce 1998). Not choosing any of the given alternatives can be perceived as maintaining the status quo, he or she may perceive the value of no-choice option as being zero. Therefore, the decision maker can reject any of the equally or similarly attractive options and adopt a nochoice option, if a no-choice option is available in the choice set. Previous studies support the notion that loss aversion causes what is called the status quo bias (Samuelson and Zeckhauser 1988; Kahneman et al. 1991).

The existence of the conflict zone is the reason why a large difference in attractiveness makes it easier to arrive at a decisive choice (Dhar 1998). When people face a choice where no single alternative has a dominant advantage, they can either avoid making a choice or purposefully manipulate their perceptions through some 'mental gymnastics' to make the perceived expected gain wide enough to justify their decision (Shafir et al., 1993; Simonson, 1989; Montgomery, 1989). One of the heuristics they adopt to resolve the conflict is the lexicographic rule whereby they select the alternative that is superior on the more important dimension, which seems to provide a compelling reason for choice (Slovic, 1975; Tverksy et al., 1988). If they fail to find the compelling reason for choice, they reject any of the presented alternatives. Even though an alternative may seem unattractive when presented alone, it can appear attractive when presented with a less attractive one (Hsee and Leclerc, 1998; Huber et al., 1982; Dhar, 1998; Tversky and Kahneman 1991). Likewise, comparison with a more attractive alternative may lower the relative value of an alternative. The result of the analysis further implies that comparison with an equally or similarly attractive alternative (i.e. alternatives with the same expected qualities) can also make the focal alternative not attractive to adopt under uncertainty.

Increased uncertainty weakens the role of the expected gain of an alternative on choice and increases the probability of rejecting all the alternatives. Consumers with high level of perceived uncertainty are likely to find all the given alternatives unattractive to choose due to the fear for potential losses. In such cases, what is in fact a good product cannot be recognized by consumers and thus cannot be adopted by them. Akerlof(1970) argues that the information asymmetry between buyers and sellers can cause market failure. This study provides a different perspective to information-related market failure. Reducing perceived uncertainty by providing more information to consumers narrows the con- 
flict zone and thus benefits what is truly a better brand (cf. Hoch and Deighton, 1986). The increased consumer expertise or knowledge is likely to reduce perceived variance of quality, thus ramify the effect of 'true' performance quality (Sen, 1998; Bhat, 1995). Providing more information generally functions as reducing perceived uncertainty and making decision making easier.

\section{Conclusion}

The literature in behavioral economics revealed that the attractiveness of a stimulus option is determined subjectively and contextually (Tversky and Kahneman 1992; Tversky and Simonson 1993; Allais, 1953). The proposed EV function is as generalization of the traditional expected utility model incorporating a more flexible and descriptive utility function to accommodate the notion of preference as a constructive, context-dependent process (Slovic, 1991; Tversky and Thaler, 1990; Kahneman and Tversky, 1979). Even though the concept of value proposed by prospect theory is widely accepted as the just substitute for the traditional concept of utility, the concept of expected value has not gained deserved attention as expected utility. It seems that it is partly due to the difficulties in explicit functional representation of the expected value. The proposed EG-EV curve and the analyses based on the EV function provide implications consistent with the results of the previous empirical and theoretical studies. In economics, psychology and marketing literature, there are a host of models that incorporate loss aversion (Tversky and Simonson 1993; Usher and McClelland 2004; Hardie, Johnson and Fader 1993; Kivetz, Netzer, and Srinivasan 2004; Rooderkerk, Van Heerde, and Bijmolt 2011), but few have been able to incorporate the effect of loss aversion and uncertainty simultaneously.

The current study has limitations. The prospect theory posits that not only the values of the outcomes but also the corresponding probabilities are evaluated subjectively (Tversky and Kahneman 1992). For the sake of simplification needed for theoretical analyses, this study rules out some of the complexities of choice and assumed that the expected value is evaluated with exact actual probabilities as they are. In addition, assuming a specific form of probability distribution (logistic distribution) for the analyses can be a factor limiting the generalizability of the analytical results. However, this modest lack of realism leads to a significant degree of mathematical convenience, and seems to have little effect on the model's qualitative properties and its implications.

〈Received September 5. 2016〉 〈Accepted October 26. 2016〉 


\section{References}

Akerlof, G. A., 1970. The market for "lemons": quality uncertainty and the market mechanism. Q. J. Econ. 84(3), 488-500.

Allais, M., 1953. Le comportement de l'homme rationnel devant le risque des postulats et axiomes de l'ecole americaine. Econometrica, 21, 503-546.

Anderson, J. R., and Bower, G. H., 1973. Human Associative Memory, V. H. Winston \& Sons, Washington, D.C.

Arrow, K. J., 1951. Alternative approaches to the theory of choice in risk-taking situations. Econometrica, 19(4), 404-437.

Barberis, N., Huang, M., Santos, T., 2001. Prospect theory and asset prices. Quart. J. Econom. 66, $1-53$

Bass, F., 1969. A new product growth for model consumer durables. 15(5), 215-227.

Benartzi, S. Thaler, R. H., 1995. Myopic loss aversion and the equity premium puzzle. Quart. J. Econom. Feb., 73-92.

Bhat, C. R., 1995. Heteroscecastic extreme value model of intercity travel mode choice. Transp. Res., 29(6), 471-483.

Carpenter, G.S., Nakamoto, K., 1989. Consumer preference formation and pioneering advantage. J. Mark. Res., 26 (August), 285-98.

Dhar, R., 1997. Consumer preference for nochoice option. J. of Consum. Res., 24(Sept.), 215-234.
Dhar, R., Simonson, I., 2003. The effect of forced choice on choice. J. Mark. Res., 40(May), 146-160.

Hardie, B. G., Johnson, E.J., Fader, P.S., 1993. Modeling loss aversion and reference dependence effects on brand choice. Mark. Sci., 12(4), 378-394.

Hoch, S. J., Deighton, J., 1986. Managing what consumers learn from experience. J. Mark., 53(April), 1-20.

Hsee, C., Leclerc, F., 1998. Product look more attractive when presented separately or together. J. Consum. Res., 25(Sep.), 175186.

Huber, J., Payne, J.W., Puto, C., 1982. Adding asymmetrically dominated alternatives: violations of regularity and similarity hypothesis. J. Consum. Res., 9(June), 90-98.

Kahneman, D., Tversky, A., 1979. Prospect theory: an analysis of decision under risk. Econometrika, 47(2), 263-291.

Kahneman, D., Knetsch, J. L., Thaler, R. H., 1991. Anomalies: the endowment effect, loss aversion, and status quo bias. J. Econ. Perspect. 5(Winter), pp.193-206

Keon, J.W., 1980. The bargain value model and a comparison of managerial implications with the linear learning model. Manag. Sci., 26 (11), 1117-1130.

Kerin, R.A., Varadarajan, P.R., Peterson, R.A., 1992. First mover advantage: a synthesis, conceptual framework, and research propositions. J. Mark., 56(October), 33-52. 
Kivetz Ran, Netzer, Oded, and Srinivasan, V. 2004. Alternative models for capturing the compromise effect," J. Mark. Res., 41 (August), 237-257.

Luce, M.F., 1998. Choosing to avoid: coping with negatively emotion-laden consumer decisions. J. Consum. Res., 24(March), 409433.

Mehra, R., Prescott, E. C., 1985. The equity premium: a puzzle," J. Monet. Econ. 15, 145-62

Rooderkerk, R. P., Van Heerde, H. J., \& Bijmolt, T. H. A. 2011. Incorporating context effects into a choice model. J. Mark. Res., 48, 767-780.

Samuelson, Paul A., (1963), Risk and uncertainty: a sallacy of large numbers, Scientia, 57 (April), 108-13.

Samuelson, W., Zeckhauser, R., 1988. Status quo bias in decision making. J. Risk Uncertain., 1(Jan.), 7-59

Schmalensee, R., 1982. Product differentiation advantages of pioneering brands. Am. Econ. Rev., 72(June), 349-65.

Sen, S., 1998. Knowledge, information mode, and the attraction Effect. J. Consum. Res., 25(June), 64-77.

Shafir, E., Simonson, I., Tversky, A., 1993. Reason-based choice. Cogn., 49, 11-36.

Simon, Herbert 1955. "A Behavioral Model of Rational Choice," Quarterly Journal of Economics, 69 (1), 99-118

Simonson, I., 1989. Choice based on reasons: the case of attraction and compromise Effects. J. Consum. Res., 16(Dec.), 158-174.

Slovic, P., 1975. Choice between equally valued alternatives. J. Exp. Psychol.: Hum. Percept. Perform., 1, 280-287.

Slovic, P., 1991. The construction of preference. Am. Psychol., 50(5), 364-71.

Thaler, R. H., Tversky, A., Kahneman, D., Schwartz, A., 1997. The effect of myopic loss aversion on risk taking: an experimental test, Quart. J. Econom., May, 647661

Tversky, A., Russo, J., 1969. Substitutability and similarity in binary choice. J. Math. Psychol, 6, 1-12.

Tversky, A., Sattath, S., Slovic, P., 1988. Contingent weighting in judgment and choice. Psychol. Rev., 95(3), 371-384.

Tversky, A., Kahneman, D., 1991. Loss aversion in riskless choice: a reference dependence model. Q. J. Econ., 107, 1039-61.

Tversky, A., Kahneman, D., 1992. Advances in prospect theory: cumulative representation of uncertainty. J. Risk. Uncertain., 297-323.

Tversky, A., Shafir, E.B., 1992. Choice under conflict: the dynamics of deferred decision. Psychol. Sci., 6(November), 5, 358-361.

Tversky, A., Simonson, I., 1993. Context-dependent preferences. Manag. Sci., 39(10), 1179-1189.

Tversky, A., Thaler, R., 1990. Anomalies: preference reversals. J. Econ. Perspect., 4(2), 201-211.

Urban, G.L., Carter, T., Gaskin, S., Mucha, Z., 
1986. Market share rewards to pioneering brands: an empirical analysis and strategic implications. Manag. Sci., 32 (June), 645659.

Usher, M., and McClelland, J. L. 2004. Loss aversion and inhibition in dynamical models of multialternative choice, Psychol. Rev., 111, 757-769

von Neumann, J., Morgenstern, O., 1944. Theory of Games and Economic Behavior. Princeton University Press, Princeton, New Jersey. 